\title{
Proof and proving in secondary school
}

\author{
Vimolan Mudaly \\ University of KwaZulu-Natal \\ Email: mudalyv@ukzn.ac.za
}

\begin{abstract}
This paper argues that mathematics should be a human activity in which the process of guided invention takes the learner through the various stages and steps of the discovery of mathematical ideas and concepts. The central premise is that proof functions as an explanation, where experimental mathematics is used to empirically convince the learner that the conjecture holds true. Inductive reasoning used while working with the computer software Sketchpad assists learners in arriving at and testing their conjectures.
\end{abstract}

\section{Introduction}

There are various definitions and conceptions of the word 'proof'. To most mathematicians, proof plays the role of verification. But does this conception of proof satisfy a similar need for the masses of people not inclined to become mathematicians? In his book, I Believe, Rampa (1977) makes the following comment:

Oh humans always want proof of everything, they even want proof that they are humans, but how can you prove a thing...If a thing is true it needs no proof because it is self evident that the thing is there, but if a thing is not true and if it is not there then no amount of 'proof' will prove that it is there so there is no point in trying to prove anything. (1977: 01)

Is this a reflection of the way proof is viewed by most people? This paper argues otherwise.

Proof-making in geometry is a difficult task in mathematics classrooms, and this surely must have contributed to the 'math-o-phobia' that has plagued schools. The evidence available shows that proving in mathematics should be left only to mathematicians. A study by Suydam (1985: 483) showed that about $50 \%$ of learners saw no need to prove what they considered obvious. Senk (1985: 454) found that only $30 \%$ of learners attained $70 \%$ mastery of six geometry problems involving proofs. Usiskin (1982) also determined that although $50 \%$ of secondary school graduates completed a year of geometry fewer than $15 \%$ mastered proof-writing. Bell (1976: 23) carried out an investigation of 160 grammar school girls and discovered that only $10 \%$ of them attained Van Hiele stage 3 - the stage at which learners could give an acceptably complete, deductive argument (proof). Reynolds (in Bell, 1979: 370) studied the "proof concepts of grammar school learners" and concluded that, in general, formal axiomatic proof was not understood even by 17 -year old learners specialising in mathematical and scientific subjects. Williams (Driscoll, 1988: 156) surveyed eleventh grade learners and found that fewer than $30 \%$ exhibited any understanding of the meaning of proof, and that almost $60 \%$ were unwilling to argue, for the sake of argument, from any hypothesis they considered false.

These statistics and the experiences of mathematics educators in general have created a sense of urgency in attempting save proof within Euclidean geometry. More importantly, an attempt should be made to resurrect the beauty of - and the need for - proof in Euclidean geometry. This paper does not engage in discussion regarding the need for proof, as much has already been written on the topic.

What is it about the way in which Euclidean geometry is traditionally taught that creates the impression that there is a need for drastic change? Many authors have been drawn to this topic and the general consensus seems to lie in the way proof is taught. Much of our teaching of proof centres on a content-driven curriculum. The emphasis is placed on the factual aspects of proof and has therefore precipitated the belief that learning of proof is simply the transmission of knowledge from the source (the educator or textbook) to the recipient (the learner). The teacher undoubtedly becomes the authoritative source of all knowledge, along with the textbook. A quick perusal of a few mathematics educational journals, will reveal that there are many methods of teaching proof which deviate from the traditional methods.

This paper does not intend to imply that the statistics listed in the opening paragraph are entirely the result of poor traditional teaching. 


\section{Vimolan Mudaly}

There are many reasons for learners' poor performances in constructing proof in examinations and class work:

- Insufficient emphasis on proof heuristics. Teachers prefer the direct teaching method, namely, presenting proof directly.

- Negative attitude as a result of not understanding the role/meaning of proof when the concept was first introduced to learners.

- Learners may be working at the incorrect Van Hiele level when attempting proof.

- The negative attitude of learners towards mathematics in general.

- The negative attitude of some teachers towards their learners and the subject.

However, traditional teaching of proof has been dominated by an authoritarian method. As Davis and Hersh (1983: 282) state: "Then there is a desire on the part of some teachers to appear brilliant. (What I'm telling you is pretty easy and obvious to me, and if you're not getting it, you really must be pretty stupid)".

Strangely enough, the view that proof is necessary only for verification has been even more dominant. The traditional role of proof has been seen mainly in terms of verification of the correctness of mathematical statements. In other words, proof serves the explicit function of convincing sceptics about the truth of a statement. Coe and Ruthven (1984: 42) summarise this in their claim that "the most salient function of proof is that it provides grounds for belief". In fact, a survey in 1984 by de Villiers (1990: 18) revealed that more than $50 \%$ of Higher Education Diploma students in mathematics education agreed that the only function of proof was that of "making sure", that is, the verification of the truth of the results.

Despite the dominance of this view, several authors have cautioned against stereotyped thinking. Bell (1976) states that:

conviction is normally reached by quite other means than following a logical proof; proof is essentially a public activity of validation which follows the reaching of conviction, though it may be conducted internally. (1976: 24)

Similarly, Hersh (1993: 390) observes that, "more than whether a conjecture is correct, mathematicians must know why it is correct". Reid (1996: 185) echoes this sentiment: "I would like to question the common assumption that the role of deductive reasoning or proving in mathematics is the verification of conjectures".

The view that proof is necessary mainly for verification often ignores a simple fact: the learner is ultimately responsible for his/her own learning and therefore his/her participation is essential. It is important to bear in mind that despite the learner's prior knowledge, s/he cannot easily make meaning of new concepts. This paper presents an argument for proof using reasoning, and make the following proposition: If evidence can be presented to a learner that would support the knowledge we want the learner to learn, in a visually-active way, then learning is made easier.

This hypothesis is based on the adage: 'I hear and I forget, I see and I remember, I do and I understand'. The approach is based on real-world and problem-centred approaches in mathematics, and is underpinned by constructivist theory. It thus accepts that "the learners have their own ideas, that these persist despite teaching and that they develop in a way characteristic of the person and the way they experience things, leads inevitably to the idea that, in learning, people construct their own meaning" (Brookes, 1994: 12).

Learners can easily determine a correspondence between what they know and the new knowledge they 'see' unfolding as they work through a realworld exercise. Often there may be a conflict between the old knowledge and the new knowledge they are discovering. Cognitive restructuring of knowledge takes place, where the new knowledge is assimilated using existing schemas that were already established. This is closely linked to the problem-centred learning (PCL) approach developed in South Africa in the mid 1980's by researchers at the University of Stellenbosch. The PCL approach is based on a socio-constructivist theory of the nature of knowledge and learning and hinges on the following aspects (Olivier, Murray \& Human, 1992):

- The learner is actively engaged in the process of acquiring knowledge.

- The learner draws on past experiences and existing knowledge.

- Learning is a social process in which new knowledge is acquired through interaction with other learners and educators. (1992: 33)

The Hans Freudenthal Institute has, since 1971, been developing the theory of Realistic Mathematics Education. This is strongly influenced by Hans Freudenthal's concept of mathematics as a human activity, and takes into consideration what mathematics really is, how it should be taught and how learners should actually learn. Selden and Selden (1999) state that:

from the perspective of Realistic Mathematics Education, students learn 
mathematics by mathematising the subject matter through examining 'realistic' situations, i.e., experientially real contexts for students that draw on their current mathematical understandings. (1999: 9)

This paper draws attention to an important consideration, that mathematics must be a human activity, which is presented in a way that resembles the manner in which it was discovered. In other words, mathematics teaching must be organised in such a way that the process of guided invention takes the learner through the various stages and steps of the discovery of mathematical ideas and concepts.

\section{Proof as a means of explanation}

The paper argues that proof serves as a means of explanation. Tiles (1991) provides a definition that encapsulates the function of proof:

By proof is meant a deductively valid, rationally compelling argument which shows why this must be so... (1991: 7)

This function of proof helps the individual make sense of a mathematical result and satisfies the individual's curiosity as to why it may be true. This aspect has been neglected because proof has been seen as performing only the function of verification. Coe and Ruthven (1984: 42) claim that less emphasis has been placed on explanation because much writing about proof "has been from a philosophical rather than a pedagogical perspective". However, Hanna (1996: 16) states that "with today's stress on 'meaningful' mathematics, teachers are being encouraged to focus on the explanation of mathematical concepts". Gale (1990) states that "the main goal of all science is to first observe and then to explain. In mathematics the explanation is the proof" [emphasis by author]. Schoenfeld (1985) sums up this important function of proof succinctly:

'Prove it to me' comes to mean 'explain

to me why it is true', and argumentation

(proof) becomes a form of explanation, a

means of conveying understanding.

(1985: 172)

Although it is possible to achieve a high level of conviction that a conjecture holds true by using experimentation, this does not provide a deeper understanding as to why the conjecture may be true (de Villiers, 1990: 19). Experimentation, especially if it is computer-driven, may provide a large degree of certainty but it does not necessarily provide the insight or understanding of how the result may be true as a consequence of other already established results. Hersh (1993: 396) states that "what proof should do for the student is provide insight into why the theorem is true" and at the high-school level, "the primary role of proof is explanation" (ibid: 398).

Anderson (1996) provides an appropriate summary of the explanatory role of proof in establishing a deeper understanding of why certain results always hold true:

Proof should be seen as being about explaining, albeit carefully and precisely.

It is where instrumental understanding gives way to relational understanding. It should be seen as the essence of mathematics and all learners who study mathematics should meet it at some time, at some level. (1996: 32)

Slomson (1996: 12) expressed the idea that "good proofs not only convince us of the truth of mathematical statements, but also helps us to understand what is going on".

A number of authors emphasise the important role of proof as a means of explanation in mathematics:

The mathematician's reaction shows quite clearly that a proof which does nothing but prove in the sense of mere verification must be unsatisfactory. A proof is also expected to generalise, to enrich our intuition, to conquer new objects, on which our mind may subsist. (Otte, 1994: 310)

The functions of proof are to generate knew knowledge and to advance mathematical understanding [emphasis by author]. (Kitcher, 1984: 189)

The best proof, even in the eyes of practicing mathematicians, is one that not only establishes the truth of a theorem but also helps understand it. Such a proof is also more persuasive and more likely

to be accepted. (Hanna, 1996: 135)

This paper thus focuses attention on the role of proof as a form of explanation.

\section{Teaching experiments}

This paper reports on two different teaching experiments conducted with learners at a secondary school. The experiments build on research conducted by de Villiers $(1990,1991)$, in the context of dynamic geometry. The purpose of the first experiment was to determine whether learners have any need for conviction and explanation within the context of dynamic geometry (Mudaly, 1999). The study also tested 


\section{Vimolan Mudaly}

curriculum material that was developed as a result of previous empirical and theoretical research. The material was designed with the aim of helping learners discover solutions to problems through a process of guided discovery in stages that are easy and practical. As the learners progressed through the worksheets, they were encouraged to record their conclusions and conjectures and so develop an explanation (proof). Seventeen learners aged about 14 years (Grade 9) were interviewed in February 1997. They were selected randomly from a group of 153 learners by their Computer Studies class teacher, who picked every ninth learner appearing in the attendance register.

The purpose of the second study was to determine whether Sketchpad could be useful as a mathematical tool when teaching learners to model (Mudaly, 2004). Although this study tested curriculum material that had already been developed (see de Villiers, 1999), it was refined as a result of previous empirical and theoretical research. Ten learners between the ages of 15 and 16 years (Grade 10) were interviewed in March 2000. They were selected randomly from a group of 60 learners by their Computer Studies class teacher.

\section{Study one}

\section{Research methods}

Learners were given a computer-based task to work through, which was based on an equilateral triangle. A sketch of the equilateral triangle was presented ready-made to the learners, although the task of constructing it for themselves might have been an interesting one. All measurements were clearly visible on the screen of the computer, so that learners could easily view any changes that might have taken place. Furthermore, the learner was actively involved in finding a solution which implied that $\mathrm{s} /$ he was ultimately responsible for his/her own learning.

This method gives credence to experimental mathematics, which involves a well-planned, sequentially structured scheme in which the learner is guided towards "discovering" a solution for him/herself. This is in keeping with scientific experiments conducted in school laboratories; the experiment is generally performed many times, and a conclusion can be drawn if the result seems to be the same every time. While traditional teaching has been teacher-centred, didactic, directive, corrective and mostly concerned with the transmission of knowledge in well-defined areas, experimental teaching in mathematics is grounded in teaching skills where the teacher acts as a facilitator.

The method employed in this study also drew on the inquisitive nature - a fundamental component - of human beings. Humans have a fundamental need to find explanations, and children in particular are inclined to ask questions such as 'why'. Most parents have been irked by endless questions such as: Why shouldn't I sit up late? Why is the sky so blue? Why must I eat my peas? Why is that man so fat? Why do I have to go to school? Why do we have to do geometry? Why is mathematics so difficult?

Furthermore, even if a child is inductively convinced about the truth of a statement, it does not constitute a reasonable proof. In other words, the fact that the sun rises every morning does not explain why it rises. There is no doubt that even if there are thick clouds in the sky we know that the sun is there behind the clouds, but it does not explain why it rises. Thus, the step that follows would require an explanation, albeit a guided one, as to why the result is true. It could also be interesting to give learners a problem in which the result only holds true for certain cases. In the

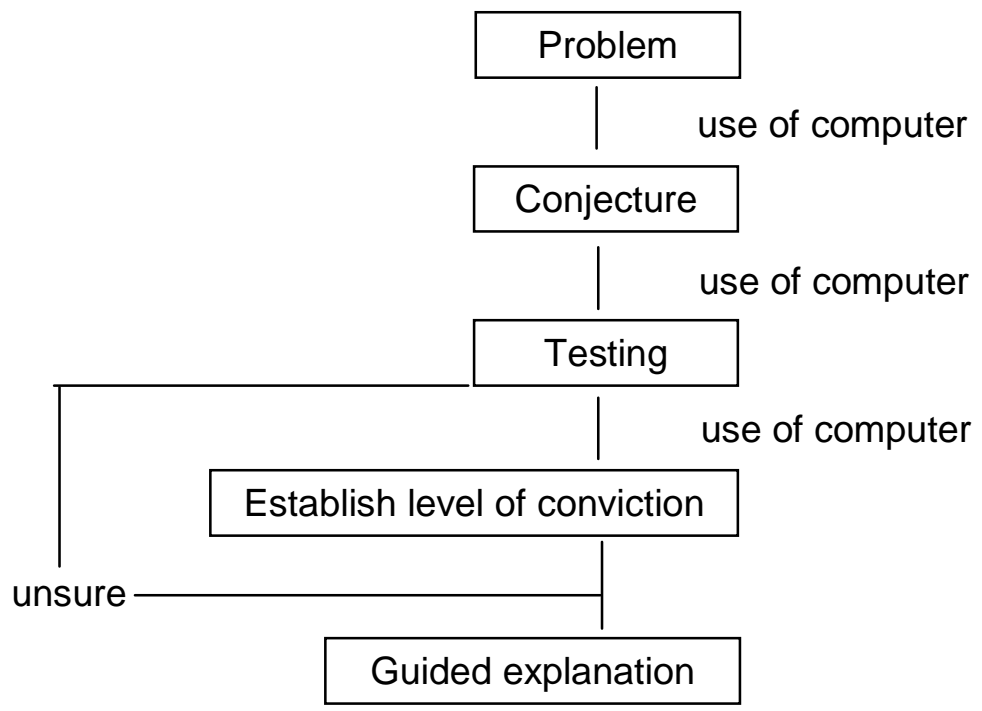

Figure 1. Flow diagram illustrating the process of experimental mathematics using computer software. 
process, the learner would undergo an experience which is bound to increase learning. A flow diagram illustrates the steps involved when using computer software in experimental mathematics (Figure 1).

The emphasis on this study is on the level of conviction attained by the learner. The experiences that are provided are owned by the learner. The learning process is thus structured around the way in which the learner experiences the problem. Critical questions that must be considered are: Can a conjecture (intuitive) be drawn? Has the learner tested the conjecture sufficiently? Is the learner convinced with the result? To what extent is the learner convinced? Can the learner explain the result? In this experiment, the learners were given the following problem to work through:

Sarah, a shipwrecked survivor, manages to swim to a desert island. As it happens, the island closely approximates the shape of an equilateral triangle. She soon discovers that the surfing is outstanding on all three of the island's coasts and crafts a surfboard from a fallen tree and surfs everyday. Where should Sarah build her house so that the total sum from the house to all three beaches is a minimum? (She visits them with equal frequency.)

\section{Study one results}

At first, all the learners intuitively guessed that Sarah should build her house at the centre. The learners were asked why they felt that the house should be built at the centre. Kumarasen, for example, responded by saying that "... if you build anything in the centre then there is always a short distance around it". Kumarasen seemed quite convinced of his conjecture and so was Manivasan, whose reason was "... because everything will be equal". Rowan believed that it should be at the centre because "it will be close ... it will be the same distance to all the beaches" and therefore the sum will be a minimum. Karishma felt that the sum would be a minimum if the point $\mathrm{P}$ was at the centre because "it will be closer to all three beaches". Ansuya's reason was similar when she said "because it seems the easiest way to get to any of the three beaches".

An equilateral triangle representing the island was then drawn on the computer using the software programme, Sketchpad. Point P was placed within the triangle. Perpendicular line segments were drawn from $\mathrm{P}$ to each side of the triangle. These line segments were measured and their sum determined. The learner was then allowed to move point $\mathrm{P}$ around and careful observation was encouraged. The learner could see the measurements of the perpendicular segments change as the point $\mathrm{P}$ was moved about. Further, they could see that the sum did not change. The surprise at discovering this result was clearly visible. The following extracts were some of the comments made by the learners.

Kerushnee: (emphatically) Yes, I find the result very surprising.

Ansuya: (confidently) Yes, I thought it would change.

Kumarasen: Yes, because at first you think it should be at the centre and the sum will be small. But now it can be anywhere.

Floyd: (emphatically) I didn't expect it. It is surprising!

It might be true that this result which the learners observed encouraged them to want to know why it was the case. The majority of learners expressed a desire for an explanation. In fact, 16 of the learners (94 percent of the total) said that they would want an explanation, and only one learner (6 percent) cogitated a while before saying that she would also like an explanation. The extracts from the interviews illustrates this desire that the learners had for an explanation.

Researcher: Do you think then, now that you are a $100 \%$ convinced, that there is a need for an explanation?

Manivasan: Yes.

Researcher: Would you want an explanation?

Manivasan: Yes.

Researcher: Why?

Manivasan: So I can understand it [learner's emphasis]

Researcher: Do you think, now that you are very convinced ... is it necessary to know why this is the case?

Rodney: Yes.

Researcher: Why do you want an explanation for this?

Rodney: To satisfy my curiosity.

Researcher: Why do you think there is a need for an explanation?

Karishma: Because I'm curious and I'd like to know what's going on. 
Researcher: Why do you think there is a need for an explanation?

Debashnee: Because I'm a curious person and I would like to find a solution for things. I would like to do the same for this.

Researcher: Do you desire an explanation for what is going on?

Ryham: Yes.

Researcher: You really would want to know why?

Rhyam: Yes.

Researcher: Why?

Rhyam: I like to find out why things are taking place.

An interesting part of this experiment focussed on whether learners were able to formulate an explanation, albeit a guided one, on their own.

Researcher: Okay, I can see that you have done that (referring to the writing down of expressions for the areas of the three small triangles). The next step asks you to add all three up. Do you know what to do?

Nicholas: Yes.

Researcher: (after a while) You've got $\mathrm{A}_{1}, \quad \mathrm{~A}_{2}$ and $\mathrm{A}_{3}$ and you've got expressions for them. Now add these expressions... (after a while) Have you done that Nicholas?

Nicholas: Yes.

Researcher: Now simplify it... Have you done that?

Nicholas: Yes.

Researcher: I've noticed that you removed half 'a' as a common factor.

Nicholas: Yes.

Researcher: Describe what you have done.

Nicholas: I've removed half ' $a$ ' as a common factor and I've got half ' $a$ ' into $h_{1}+h_{2}+h_{3}$.

Researcher: Nicholas can you tell me how these three triangles relate to the area of the large triangle?

Nicholas: The area of the three triangles when you add it up, will give you the area of the big triangle.

Researcher: If that is the case and we found the sum of the areas of the three triangles, then what can we conclude?

Nicholas: (silence)
Researcher: That the areas of these triangles equal the ... ?

Nicholas: ... area of the big triangle.

Researcher: Now look at E4. I want you to write down this expression.

Nicholas: (after a while) I noticed that the big triangle also had half ' $a$ ' in it. So I cancelled off the half ' $a$ ' from the big triangle and half ' $a$ ' from the three small triangles.

Researcher: And what have we arrived at?

Nicholas: The height of the three triangles... when you add it up it gives you the height of the big triangle.

Researcher: What does this mean to you?

Nicholas: No matter what the heights of the three smaller triangles are, it will always equal the height of the big triangle.

Researcher: So what does it mean in terms of Sarah's house?

Nicholas: It means that no matter where she puts her house the total distances will always be constant.

The ability of the learners to formulate conjectures and subject them to critical tests was admittedly lacking. However, it is more difficult to relate the formal proof, as it is taught in the ostensive way, to learners' past experiences. Ultimately, proof is necessary to see why the conjecture always holds true, rather than whether or not it will hold true. This suggests that proof in schools should reflect the idea of an explanation instead of the idea of verification. When a teacher states directly that a theorem is correct, the learner sees no need to verify it. In contrast, where a proof is presented as a means of explanation and further understanding - as is being advocated by many mathematicians and mathematics educators - it may be possible to address the current crisis in school geometry.

In the context of this study, it becomes evident that learners inherently attempt to find explanations, however simplistic they might be. Their desire to know why is authentic, and not just a hypothetical assumption of some theorist, as was demonstrated in this teaching experiment. When the learners were asked to attempt an explanation they were always willing to try. This may be because their level of conviction was always very high (the learners, after seeing the results on the computer generally indicated that they were $90 \%$ 
to $100 \%$ convinced.) Conviction alone is insufficient when teaching proof. In this experiment the learners were given a worksheet that gave appropriate directions for developing an explanation. Guided through each step, the learners had a good understanding of the explanation. In fact, many of them indicated that this was a good explanation, which is encouraging considering their antipathy towards geometry classes. This experiment is still in process, and it should be noted that those learners that have gone through this process are keen to get back into the computer laboratory for further interviews.

\section{Study two}

\section{Research methods}

In the second study, the learners investigated perpendicular bisectors of quadrilaterals and triangles. The question they were given was:

In a developing country like South Africa, there are many remote villages where people do not have access to safe, clean water and are dependent on nearby streams or rivers for their water supply. With the recent outbreak of cholera in these areas, untreated water from these streams and rivers has become dangerous for human consumption. Suppose you were asked to determine the site for a water reservoir and purification plant so that it would be the same distance away from four remote villages. Where would you recommend the building of this plant?

They were then given a modelling exercise in which they were required to work with two villages, four villages and then three villages. The reason for this particular order is not discussed in this paper.

\section{Study two results}

At first, the learners attempted to solve the problem directly, before moving on to the modelling exercise. Unlike quadrilaterals, the perpendicular bisectors of every triangle they constructed, using Sketchpad, showed that the perpendicular bisectors were concurrent. This raised the curiosity of the learners and I then asked them whether they would like to know why the perpendicular bisectors of the triangle were always concurrent. All learners indicated a desire for an explanation, and shared a similar reason: they were surprised at what they had experienced.

Judging by the tone of their voices, it could be said that most of them were quite enthusiastic about working through an explanation. One learner initially seemed uncertain, but eventually admitted that he was surprised at the results and would be interested to find out why. Several learners felt that it would be interesting to know "why the result was always true" and that "it would be useful to know why the result is true". Christina's need for an explanation was significant:

Researcher: Would you want to know why this result is always true?

Christina: Yes...I can see it is true but maybe if there is a proof for it I'll understand it better.

She showed a very high level of conviction when she stated, "I can see it is true" and yet she felt that her understanding would be increased if she worked through a proof. This indicates that the level of conviction obtained from working with dynamic geometry software may stimulate further curiosity, which can be used as a starting point for proof.

Roxanne also felt that an explanation would show her why the result obtained for all triangles was different from that obtained for quadrilaterals.

Researcher: Would you want to know why this is always true?

Roxanne: Yes... maybe it will explain why it was different.

The fact that she saw that the results were distinctly different for the cases for two and four villages kindled in her the desire to want to know why this was the case. This also clearly indicates that different individuals show different needs when working with proof in geometry. Whilst some felt that it would be useful just to know why, others felt that an explanation will give them greater understanding.

Researcher: Would you like to know why the perpendicular bisectors are always concurrent?

Pravanie: I guess that it would be useful to know.

Researcher: Would you like to know why this is always true?

Faeeza: It might be interesting to know...I can't believe it (showing surprise).

Researcher: Would you like to know why this is always true?

Nigel: Definitely...maybe I could trick my friends too. 
Researcher: Would you like to know why this is always the case?

Schofield: What do you mean sir?

Researcher: Do you want to know why the perpendicular bisectors are always concurrent?

Schofield: I don't know... mmm... yes, maybe it will be interesting.

Researcher: You think that this would be interesting?

Schofield: Yes...I was surprised at the results.

It should perhaps be noted again that Ausubel's learning theory suggests that meaningful learning occurs as a result of stimulating the learners' curiosity during a discovery process (Ausubel, Novak \& Hanesian, 1978). It seems as if the difference in their findings for the quadrilateral and triangle stimulated their curiosity, and created a desire for some form of explanation.

The explanation for the concurrency of perpendicular bisectors of all triangles was based on materials developed by de Villiers (1999: 32). Below are extracts of interviews with the learners.

Researcher: Construct the perpendicular
bisector of any side.
Desigan: Can I do it for AB?
Researcher: Yes. (after the construction)
Desigan, what can you tell me about
all the points on this perpendicular
bisector?
Desigan: It is equidistant from A and B.
Researcher: What is equidistant?
Desigan: All the points on this line
(pointing to the perpendicular
bisector).
Researcher: What does that really mean
to you?
Desigan: If you measure the distance
from any point on this line to this A
and B, the distance will be the same.

In this segment, attempts were being made to stimulate the learners to recall the concepts of perpendicular bisector and equidistance. In a way, it was also a means of determining whether the learners actually understood and remembered what they had done earlier in the interview. Vischalan displayed a similar understanding of the concept of equidistance.

\section{Researcher: Look at this triangle on the} screen. Construct the perpendicular bisector of side AC. (after the construction) what can you tell me about all the points on this perpendicular bisector?

Vischalan: They are the same distance away from $\mathrm{A}$ and $\mathrm{B}$.

Researcher: What is the term used to describe same distance away?

Vischalan: Equidistance.

Researcher: So what are you saying about all points on this line?

Vischalan: All the points on this line (pointing to perpendicular bisector) are equidistance from $\mathrm{A}$ and $\mathrm{C}$.

Researcher: Equidistant - not equidistance - from $\mathrm{A}$ and $\mathrm{C}$. What does that really mean to you?

Vischalan: If you calculate the distance from any point to $\mathrm{A}$ and then to $\mathrm{C}$ the distance will be exactly the same.

It was clear that the learners had developed a good grasp of this concept (equidistance) and that the researcher could therefore continue with the rest of the explanation. The next part of the explanation was similar in that it required the learners to construct another perpendicular bisector to relate the point of intersections of the two perpendicular bisectors to the three vertices. This relationship between the intersection and the three vertices did not take long to achieve, although in Desigan's case it was obvious that he made a mistake at one point in the interview but he did correct himself.

Researcher: Now construct any other perpendicular bisector.

Desigan: (constructing)

Researcher: What can you tell about the points on this line now?

Desigan: All the points are the same distance away from B and C.

Researcher: Now look at this point of intersection. What can you say about this point in particular?

Desigan: Eh ... eh...

Researcher: Think carefully about the point.

Desigan: That point there is the same distance away from $\mathrm{A}$ and $\mathrm{B}$, and $\mathrm{B}$ and $\mathrm{C}$.

Researcher: A and B, and B and C?

Desigan: Yes, it is the same distance away from A, B and C.

Researcher: Are you sure? 
Desigan: It lies on this line so it must be equidistant from $\mathrm{A}$ and $\mathrm{B}$ and it lies on that line so it must be equidistant from $\mathrm{A}$ and $\mathrm{C}$.

Researcher: If it lies on that line would it be equidistant from $\mathrm{A}$ and $\mathrm{C}$ ?

Desigan: No, B and C.

Researcher: Now construct perpendicular bisector of $\mathrm{AB}$.

Vischalan: (constructing)

Researcher: What can you tell about the points on this line now?

Vischalan: All the points are equidistant from $B$ and $A$.

Researcher: Now look at this point of intersection. What can you say about this point in particular?

Vischalan: That is the point of concurrency of these two perpendicular bisectors.

Researcher: Yes, that is true, but think carefully about the point. What is special about it?

Vischalan: It is equidistant from A, B and C.

Researcher: Really? Why?

Vischalan: It is equidistant from $\mathrm{A}$ and $\mathrm{C}$, and then it is equidistant from $\mathrm{A}$ and $\mathrm{B}$, then it must be equidistant from $\mathrm{A}$, $\mathrm{B}$ and $\mathrm{C}$.

It was also quite interesting to note the level of reasoning that these learners were able to achieve and their ability to employ the basic transitive property. For example, if $a \otimes b$ and $b \otimes c$, then $a \otimes c$ (where $\otimes$ represents a general binary relationship). It implies that these learners had reached the stage of Van Hiele Level 3 (Usiskin, 1982). They could see the deductive logic in the explanation as they were being guided through it. Being able to ascertain that if the point was equidistant from $\mathrm{A}$ and $\mathrm{B}$ and then from $\mathrm{B}$ and $\mathrm{C}$, therefore the point must be equidistant from $\mathrm{A}, \mathrm{B}$ and $\mathrm{C}$ is characteristic of Van Hiele Level 3.

Furthermore, they seemed convinced that their reasoning was correct. The researcher attempted to get them to measure the distance just to check, but the learners felt that this was not necessary.

Researcher: So are you sure that this point of intersection is the same distance away from $\mathrm{A}, \mathrm{B}$ and $\mathrm{C}$ ?

Vischalan: Yes.
Researcher: Don't you want to measure and check?

Vischalan: No...it's not necessary.

The next aspect was particularly important because it would be the real test as to whether the learners understood this concept of equidistance.

Researcher: This you have to think very carefully about. What can you say about the perpendicular bisector of $\mathrm{AC}$ ?

Desigan: All the points will be equidistant from $\mathrm{A}$ and $\mathrm{C}$.

Researcher: Yes, that is correct. But look at the other perpendicular bisectors.

Desigan: Oh yes, it must pass through the point where these two lines meet (pointing to the perpendicular bisectors).

Researcher: What can you say about the perpendicular bisector of $\mathrm{BC}$ ?

Vischalan: (silence)

Researcher: Think about it... What can you say about the perpendicular bisector of BC?

Vischalan: I think ... it will pass through this point of intersection here.

The researcher was aware that the learners may have just guessed the response because they already knew that the perpendicular bisectors of the triangle were concurrent. Therefore the response that followed was essential in determining whether they were making a response with understanding or not.

Researcher: Really? Do you really think so?

Vischalan: Yes, I'm quite sure.

Researcher: Why?

Vischalan; Well if I construct the perpendicular bisectors, all the points on that line must be equidistant from $\mathrm{B}$ and $\mathrm{C}$.

Researcher: Yes, go on.

Vischalan: What do you mean?

Researcher: You just said that all the points on that line must be equidistant from $B$ and C. So what does that mean?

Vischalan: That point of intersection has to pass through the point of intersection ... it has to because that point is also equidistant from $\mathrm{B}$ and $\mathrm{C}$. 


\section{Vimolan Mudaly}

Researcher: Really? Why?

Desigan: Yes, because if all the points on this perpendicular bisector of $\mathrm{AC}$ are the same distances away... then... then this point of intersection is also the same distance away... then...

Researcher: Yes?

Desigan: Then the line must pass through the point of intersection.

It was clear that these learners had actually grasped the concept of equidistant points. Nevertheless, it was not surprising that the learners wanted to see whether their conjecture was true. This indicated that they where still sceptical. They knew that they were correct, but they wanted to see it nonetheless. Furthermore, it was interesting to note that the learners were actually taking ownership of the explanation.

Researcher: Do you want to see whether
that is true?
Desigan: Yes.
Researcher: Construct the perpendicular
bisector of AC then.
Desigan: (after constructing) This is so
easy.
Researcher: Was it really that easy?
Desigan: I didn't take so long to get it
right!

Researcher: Do you want to see whether
that is true?
Vischalan: Yes.
Researcher: Construct the perpendicular
bisector of BC then.
Vischalan: (after constructing) I was
right again.

It was encouraging to note that the actual explanation became much easier because of the way the different problems were modelled. The learners made use of their existing knowledge to deductively construct an explanation, even though they were guided through it. Their high levels of understanding (confirmed by the way in which they responded) helped them to arrive at an explanation with ease.

It should be noted that this is not the normal textbook proof conducted in South African schools (which is based on congruency). However, it is a valid proof that appears to have increased learners' understanding.

\section{Conclusion}

This research has highlighted some valuable insights regarding teaching and learning geometry theorems and problems. Given the fundamental importance of proof within mathematics as a discipline, proof should remain an essential part of the secondary school curriculum. Moreover, the teaching (and learning) approach used in this empirical research seems to have provided learners with an improved, and more meaningful, understanding of the role of proof. This study has focussed mainly on the introduction of proof to learners as a means of explanation, rather than as verification.

The research demonstrates how learners have a need for an explanation (deeper understanding) which is independent of their need for conviction. It would appear that the learners exhibited an intrinsic desire for an explanation, even though they had a high level of conviction with respect to their conjecture. Such conviction often reduces a problem to the realm of the obvious, in other words, 'I can see that it is true so why do I need an explanation for it?' If the learners were so sure of the result then it should have made no difference to them whether there was some logical explanation for it or not. Yet they expressed a strong desire for an explanation. It seemed that they had recognised the fact that they had merely observed the result through experimentation. The learners were aware of the difference that existed between observation, through experimentation, and knowing why it was really true. They undoubtedly wanted to know why the result was true and not whether the result was true. From the learners' responses it seemed that the explanation provided insight into the reason why it was true.

More significantly, this research has found that with appropriate guidance, learners can construct reasonable explanations for their conjectures. The learners involved in these teaching interventions, showed that, with guidance, they could construct a proof. In a sense, the act of moving points on a screen and seeing the results displayed on the screen is a type of proof in itself. Constructing a logical argument thereafter became much easier, because seeing the images on the screen allowed the learners to see the generalisation in the particular diagrams they were constructing.

Although the two studies worked with very small groups of learners, it is possible to extrapolate these results to most learners. These groups were drawn from 'below average' classes, which permits a certain level of generalisation in the South African context. The fact that the 
learners in this study were guided through the explanation (proof) should not detract from the findings, as this approach is in keeping with Vygotsky's Zone of Proximal Development (Morris, 2007).

Although the one-on-one interactions do not resemble typical classroom teaching, it is safe to hypothesise that even more productive interactions would take place in the dynamic classroom context. If learners are able to hypothesise and attempt explanations individually, then they should be able to solve problems even more effectively in a collective situation. This would require a classroom environment in which interaction with peers is encouraged. Investigation of this aspect in future research may provide further useful insights.

\section{References}

Anderson, J. (1996). The place of proof in school mathematics. Mathematics Teaching, 155, 3339.

Ausubel, D.P., Novak, J.D. \& Hanesian, H. (1978). Educational Psychology: A cognitive View. New York: Holt, Rinehart \& Winston.

Bell, A.W. (1976). A study of pupils' proofexplanations in mathematical situations. Educational Studies in Mathematics, 7, 23-40.

Bell, A.W. (1979). The learning of process aspects of mathematics. Educational Studies in Mathematics, 10, 361-387.

Brookes, D.W. (1994). The Nature of Conceptual learning and thinking. Unpublished article. University of Durban-Westville.

Coe, R \& Ruthven, K. (1984). Proof practices and constructs of advanced mathematical students. British Educational Research Journal, 20(1), 41-53.

Davis, P.J. \& Hersh, R. (1983). The Mathematical Experience. London: Pelican Books.

De Villiers, M.D. (1990). The role and function of proof in mathematics. Pythagoras, 24, 17-24.

De Villiers, M.D. (1991). Pupils' needs for conviction and explanation within the context of geometry. Pythagoras, 26, 18-27.

De Villiers, M.D. (1999). Place Kicking Locus in Rugby. Pythagoras, 49, 64-67.

Driscoll, M. (1988). Research Within Reach: Secondary School Mathematics (6 ${ }^{\text {th }}$ Edition). Virginia: NCTM.

Gale, D. (1990). Proof as explanation. The Mathematical Intelligencer, 12(1), 9-15.
Hanna, G. (1996). The Ongoing value of proof. In M.D. de Villiers \& F. Furinghetti (Eds.), Proceedings of Topic Group 8: Proofs and Proving: Why, When and How? (pp 1-12). Centrahil: AMESA.

Hersh, R. (1993). Proving is convincing and explaining. Educational Studies in Mathematics, 24(4), 421-438.

Kitcher, P. (1984). The Nature of Mathematical Knowledge $\left(1^{\text {st }}\right.$ Edition). New York: Oxford University Press.

Morris, C. (2007). Lev Semyonovich Vygotsky's Zone of Proximal Development. Retrieved August 2007 from http://www.igs.net/ cmorris/ zpd.html

Mudaly, V. (1999). Pupils' needs for conviction and explanation within the context of dynamic geometry. Unpublished masters thesis, University of Durban-Westville, Durban.

Mudaly, V. (2004). The Role and Function of Sketchpad as a Modelling tool in Secondary Schools. Unpublished doctoral thesis, University of KwaZulu-Natal, Durban.

Olivier, A., Murray, H. \& Human, P. (1992). Problem-centred Learning: the case of division. Pythagoras, 28, 33-36.

Otte, M. (1994). Mathematical Knowledge and the Problem of Proof. Educational Studies in Mathematics, 26, 299 - 321.

Schoenfeld, A.H. (1985). Mathematical Problem Solving ( $1^{\text {st }}$ Edition). Orlando: Academic Press.

Reid, D. (1996). The Role of Proving: Students and Mathematicians. In M.D. de Villiers \& F. Furinghetti (Eds.), Proceedings of Topic Group 8: Proofs and Proving: Why, When and How? (pp 185-198). Centrahil: AMESA.

Selden, A. \& Selden, J. (1999). Tertiary Mathematics Education research and its Future. Technical report No. 1999-6, Tennessee Technological University. Retrieved July, 2007 from www.math.tntech.edu/techreports/reports. html

Senk, S.L. (1985). How well do students write geometry proofs? Mathematics Teacher, 78, 448-456.

Simpson, A. (1995). Developing a proving attitude. Proceedings of justifying and proving in school mathematics (pp 39-46). London: University of London.

Slomson, A. (1996). Mathematical proof and its role in the classroom. Mathematics Teaching, 155, 10-13. 


\section{Vimolan Mudaly}

Suydam, M. N. (1985). The Shape of Construction in Geometry: Some highlights from Research. Mathematics Teacher, 79, 481-485.

Tiles, M. (1991). Mathematics and the image of reason $\left(1^{\text {st }}\right.$ Edition). London: Routledge.
Usiskin, Z.P. (1982). Van Hiele levels and achievement in secondary school geometry. Unpublished report, Department of Education, University of Chicago, Chicago, IL. Retrieved November, 2006, from http://socialsciences. uchicago.edu/ucsmp/Van_Hiele_Levels.pdf

"Even fairly good students, when they have obtained the solution of the problem and written down neatly the argument, shut their books and look for something else. Doing so, they miss an important and instructive phase of the work. ... A good teacher should understand and impress on his[/her] students the view that no problem whatever is completely exhausted.

One of the first and foremost duties of the teacher is not to give his[/her] students the impression that mathematical problems have little connection with each other, and no connection at all with anything else. We have a natural opportunity to investigate the connections of a problem when looking back at its solution." 